\title{
Evaluation of two ozone air quality modelling systems
}

\author{
S. Ortega ${ }^{1}$, M. R. Soler ${ }^{1}$, J. Beneito ${ }^{1}$, and D. Pino ${ }^{2,3}$ \\ ${ }^{1}$ Department of Astronomy and Meteorology, University of Barcelona, Avd. Diagonal 647, 08028 Barcelona, Spain \\ ${ }^{2}$ Institute for Space Studies of Catalonia, Edifici Nexus 2, Gran Capità 2-4, 08034 Barcelona, Spain \\ ${ }^{3}$ Applied Physics Dept., Technical Univ. of Catalonia, Avd. Del Canal Olímpic s/n, 08860 Castelldefels, Barcelona, Spain
}

Received: 30 September 2003 - Published in Atmos. Chem. Phys. Discuss.: 24 March 2004

Revised: 9 July 2004 - Accepted: 29 July 2004 - Published: 25 August 2004

\begin{abstract}
The aim of this paper is to compare two different modelling systems and to evaluate their ability to simulate high values of ozone concentration in typical summer episodes which take place in the north of Spain near the metropolitan area of Barcelona. As the focus of the paper is the comparison of the two systems, we do not attempt to improve the agreement by adjusting the emission inventory or model parameters.

The first model, or forecasting system, is made up of three modules. The first module is a mesoscale model (MASS). This provides the initial condition for the second module, which is a nonlocal boundary layer model based on the transilient turbulence scheme. The third module is a photochemical box model (OZIPR), which is applied in Eulerian and Lagrangian modes and receives suitable information from the two previous modules. The model forecast is evaluated against ground base stations during summer 2001. The second model is the MM5/UAM-V. This is a grid model designed to predict the hourly three-dimensional ozone concentration fields. The model is applied during an ozone episode that occurred between 21 and 23 June 2001. Our results reflect the good performance of the two modelling systems when they are used in a specific episode.
\end{abstract}

\section{Introduction}

Ozone has recently become a problem pollutant in both industrial and rural areas of southern Europe (Silibello at al., 1998; Grossi et al., 2000) during spring and summer. It is associated with increasing emissions of nitrogen oxides and organic compounds, which, activated by solar radiation, produce ozone in the planetary boundary layer. Evidence of this is provided by the elevated ozone concentrations measured

Correspondence to: S. Ortega

(sortega@am.ub.es) in the last few decades in urban and industrial areas and especially in many downwind rural areas, where local ozone precursors are lacking.

For several reasons, tropospheric ozone is considered to be one of the worst pollutants in the lower troposphere. A higher concentration of tropospheric ozone can contribute to a potentially important climate forcing, which needs to be properly assessed (Chalita et al., 1996). It is toxic to plants so it reduces crop yields (Guderian et al., 1985; Hewitt et al., 1990). To humans it acts as a respiratory irritant that reduces lung function (Lippmann, 1991). It also damages both natural and artificial materials such as stone, brickwork and rubber. Controlling and forecasting ozone concentrations can therefore benefit humans, vegetation and the economy. This control is also needed for assessing the scale of ozone impacts and for developing control strategies through appropriate measurements and modelling.

In the last three decades, significant progress has been made in air-quality modelling systems. The simple Eulerian box models have evolved into complex variable-grid models. The early box models were a first approach to incorporating the complex chemistry that links primary and secondary pollutants and to including some meteorological variables, but they were an oversimplification of the processes and mechanisms that act in the troposphere. The Lagrangian box models were improvements of the Eulerian box models because the column of air (the box) moved along the trajectory of certain initial pollutant concentrations. In fact, they were an expansion of the simple box model to a series of adjacent, interconnected boxes.

The most recent models are grid-based or Eulerian-grid models. The area to be modelled is divided into grids, or boxes, in both the horizontal and vertical directions. This kind of model takes into account interactions between the different cells and involves many physical and chemical processes but requires a complete description of the zone in which they are applied. This is usually more extensive than 


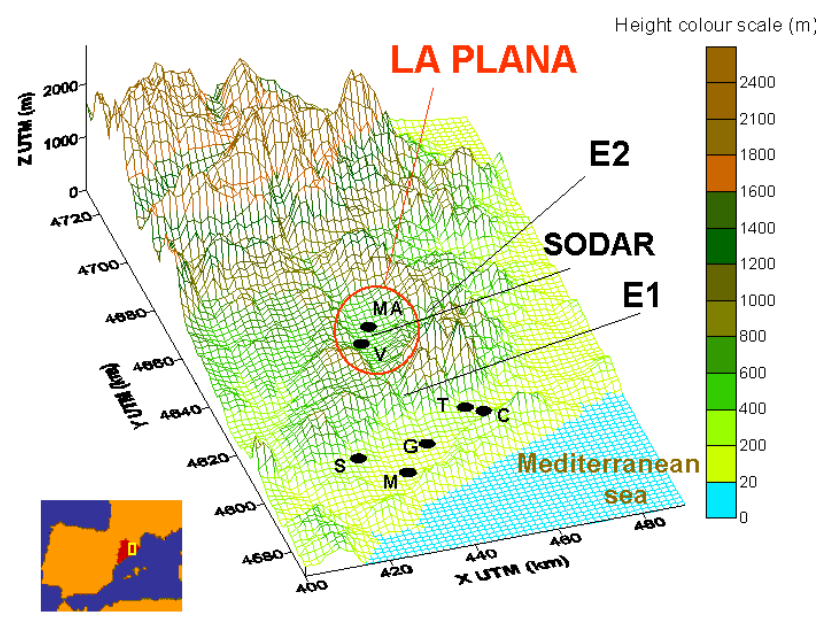

Fig. 1. Orography of the studied area. The black points are the location of the measurement stations.

in box models, which makes it more difficult to obtain successful results.

Today many photochemical models are applied in different parts of the world. Sufficient good results have been obtained in the modelling of tropospheric ozone. However, few models have been used in Catalonia (NE Spain), which has an important industrial area on the coast around Barcelona. This area acts as an important anthropogenic source of ozone and precursors, which increases the air pollution, especially of ozone, in a neighbouring area called La Plana. This is a topographically complex area northeast of Barcelona (see Sect. 2 for a detailed description). One of the causes of this increased air pollution, apart from its own production, is pollutant advection from the area of Barcelona to La Plana via sea breeze, which penetrates further inland to reach the whole area. La Plana also frequently presents stagnating meteorological conditions that, coupled with high solar radiation, lead to maximum ozone levels that exceed the threshold prescribed. This is why in this study we apply two different models to this area to forecast ozone concentration.

The first modelling system is a photochemical box model (OZIPR), which has been applied in an Eulerian and Lagrangian modes. Beside, this modelling system is integrated by a meteorological module composed by a mesoscale model (MASS) which provide the trajectory followed by the box model when it is applied in a Lagrangian mode and the initial condition to a non local boundary layer model based on the transilient turbulence scheme model.

The second modelling system is made up of a threedimensional grid-based photochemical model (UAM-V) applied in a non-nested mode and a mesoscale model (MM5) that provides the meteorological conditions for the photochemical model. This system was applied in a small domain covering part of the industrial zone near Barcelona and the whole of La Plana, where high ozone levels are frequently observed.
The importance of emissions in photochemical models is well known. For this reason an emission model covering the whole area in which the models were applied was integrated in order to supply the corresponding emissions from surface and elevated sources.

Section 3 presents a detailed description of both modelling systems. Section 4 describes the emission model. Section 5 presents the model applications, the results, the discussion and validation of the models and section 6 compares the models. Finally, Sect. 7 provides some concluding remarks.

\section{The experiment}

\subsection{Area characteristics}

The area we studied, La Plana (see Fig. 1), is a large basin, a plateau surrounded by mountains that are very often over $1000 \mathrm{~m}$ above sea level. La Plana is between $450 \mathrm{~m}$ and $600 \mathrm{~m}$ above sea level. With regard to atmospheric circulation, this zone is almost isolated, with only two exits. In the south, the Congost exit, $\mathrm{E}_{1}$, is situated between the Tagamanent and Berti Mountains. In the east, the Les Guilleries exit, $\mathrm{E}_{2}$, is situated between two high mountain ranges.

This complex topography makes for a particularly thermic and dynamic regime in the area studied (Soler et al., 2003). In this section, we highlight only two phenomena that have a climatic value due to their frequency. The first one is the stagnation that takes place at night, usually in anticyclonic situations, when the wind regime is calm (an average of $77 \%$ of the data analysed). The height of this stagnation is roughly $100 \mathrm{~m}$, which causes stagnant cold air masses, the formation of strong thermic inversions and fog. Especially in winter, the number of days with fog can be as much as 80 a year. The second phenomenon is the occurrence of a sea breeze. This starts in spring and ends in autumn and increases ozone concentrations and related primary and secondary pollutants. This area, therefore, has pollution problems caused mainly by the weak dispersive capacity of its air and the arrival of pollutants from industrial coastal areas when the wind regime is dominated by the sea breeze. These factors lead to maximum ozone levels in which the $180 \mu \mathrm{g} \mathrm{m}^{-3}$ threshold is exceeded a few days every year. High ozone levels in the area require a careful strategies for reducing the emission of primary pollutants and reaching the prescribed health and environmental targets.

\subsection{Meteorological and air pollution data}

In this study we used data from meteorological and air quality ground stations at Sabadell (S), Granollers (G), St Celoni (C), Sta. Ma de Palautordera (T), Vic (V), Manlleu (MA) and Mollet (M), which are located inside and outside the La Plana region (Fig. 1) and belong to a network of surface stations. Every $30 \mathrm{~min}$ they provide data about solar radiation, 
temperature, wind speed and direction, relative humidity, and $\mathrm{CO}, \mathrm{NO}, \mathrm{NO}_{2}$ and $\mathrm{O}_{3}$ concentrations.

In addition, a Doppler Sodar reported measurements of the boundary layer structure in complex terrain. The Doppler Sodar used in this experiment was the SCINTEC MFAS64 SODAR, which was largely described in Soler et al. (2003). Measurements of the three wind components, their standard deviation and echo intensity, which provide vertical atmospheric thermal structure, were stored in 15 min mean value. The Doppler Sodar was deployed in the Manlleu area (SODAR in Fig. 1), which is situated in the lowest part of La Plana.

\section{Modelling systems}

\subsection{Box model}

The box modelling system is made up of three fundamental modules containing two meteorological models, a column or a box photochemical model and an emission model, respectively. In this section we will briefly describe the first two modules and in Sect. 4 we will describe the emission model, which is shared by the two modelling systems.

The meteorological module comprises two models. The first one was an upgrade of the Mesoscale Atmospheric Simulation System, hereafter referred to as MASS (Kaplan et al., 1982; Zack and Kaplan., 1987), which is the operational model of the Catalonian Weather Service. The second one was a 1-D atmospheric boundary layer (ABL) model based on transilient turbulence scheme (Stull, 1984).

MASS is a 3-dimensional hydrostatic primitive mesoscale model executed with two domains one way nested, which are defined using resolutions of 30 and $8 \mathrm{~km}$. The dimensions of each domain are $55 \times 55$ grid points for the outer domain and $103 \times 103$ grid points for the inner domain. The biggest domain is centred at $(40.00 \mathrm{~N}, 10 \mathrm{E})$ and the smallest domain is centred at $(41.00 \mathrm{~N}, 3.00 \mathrm{~W})$, covering an area from $37.5 \mathrm{~N}$ to $44.5 \mathrm{~N}$. The initial and boundary conditions are updated every six hours with information from the AVN model with a $0.55^{\circ} \times 0.55^{\circ}$ resolution. For both domains, we used a topography and land-use data base with $10 \mathrm{~min}$ resolution. High vertical resolution is prescribed in the ABL with 21 levels, with higher resolution on the lower levels. More information about model physics and numerics are described in Codina et al. (1997).

The 1-D atmospheric boundary layer model is based on the non-local transilient turbulence closure (Stull, 1984; Stull and Hasegawa, 1984), which was first developed by R. B. Stull as an alternative to local closure schemes such as K-theory and higher-order closure. In this approach, we used the matrix of mixing (transilient) coefficients developed by Stull and Driedonks (1987) and calculated from a simplified form of turbulence kinetic energy. In the model, each time step is split into two parts. In the first one, external forcing (e.g. the dynamics, thermo-dynamics, boundary conditions) destabilize the flow, and in the second one the transilient turbulence scheme reacts to instabilities via mixing. In this way mean wind, potential temperature and specific humidity are destabilized by momentum and sensible and latent heat fluxes from the ground. Surface momentum fluxes are calculated using the drag coefficient method, while sensitive and latent heat fluxes are calculated using the Blackadar $(1976,1979)$ surface model. In addition, turbulence profiles of kinematic turbulent fluxes are calculated using the transilient turbulent closure scheme. With this information we were able to calculate the height of the boundary layer, defined as the height of most negative heat flux or as the average base of the overlying stable layer. The height of the boundary layer is the height of the photochemical box model. It is therefore very important to correctly estimate it in order to determine the ozone concentration (Berman et al., 1997).

The photochemical model used in this study was the OZIPR model (Ozone Isopleth Plotting Programme, Research), (Gery and Crouse, 1990). This is a column or a box model developed by the EPA (Environmental Protection Agency). It is a single day forecast model designed to focus on the atmospheric chemistry that leads to ozone formation. The chemical mechanism we used in this paper was the carbon bond approach (Gery et al., 1989; Stockwell et al., 1990). Dry deposition at the surface is included in the model in a simple way. For each species, values are fixed for two types of surface - urban and rural.

This idealized column contains specified initial concentrations of VOC, $\mathrm{CO}$ and $\mathrm{NO}_{\mathrm{x}}$, and updated emissions from the surface and elevated sources are included during the day. The model is executed in Eulerian and Lagrangian modes. In the first mode, the air mass, which is taken as $20 \times 20 \mathrm{~km}^{2}$ over a region, is treated as a box in which pollutants are emitted. Transport into and out of the box by meteorological processes and dilution is taken into account. However, in this Eulerian mode, mesoscale effects such as sea breeze are not considered. To take this into account, therefore, the box model must be applied in the Lagrangian mode following the trajectory, which is calculated using a backtrajectory model (Alarcon et al., 1995; Alarcon and Alonso, 2001). For more accurate information to obtain trajectories than those provided by MASS model (horizontal resolution $8 \mathrm{~km}$ ), the MM5 model with a $1 \mathrm{~km}$ resolution is executed. The trajectory integration domain is located in Vic $(\mathrm{V})$ and covers a $1 \mathrm{~km}$ resolution grid of $60 \times 90$ grid points.

\subsection{Grid model}

The other photochemical model we used was the threedimensional grid-based Variable-Grid Urban Airshed Model (UAM-V), version 1.30 (fast chemistry solver).

This model has been widely used for regulatory purposes (Biswas et al., 2001). The UAM-V modelling system employs an updated version of the original Carbon Bond IV 


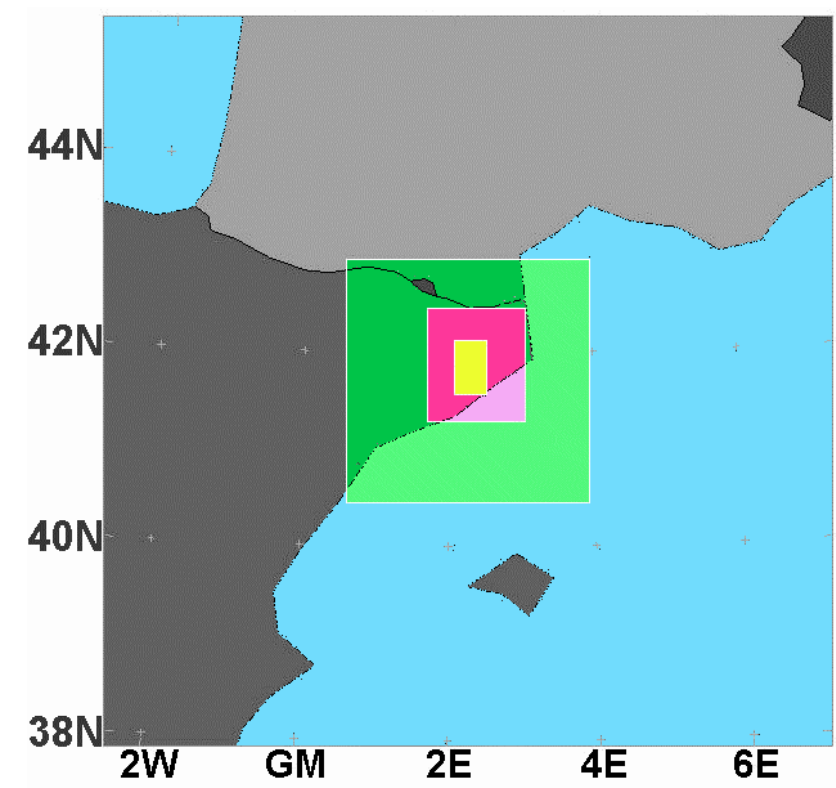

Fig. 2. The 4 domains of the MM5 simulation. The inner domain is the same used by UAMV.

chemical kinetics mechanism (Gery et al.,1989), which contains the CB-TOX mechanism (Ligocki and Whitten, 1992; Ligocki et al., 1992). In addition to the isoprene update, this includes an expanded chemical treatment for aldehydes and selected toxic species. Considering so many species takes the model closer to reality. However, emissions and initial and boundary conditions must take into account all of these species, and as their behaviour is not always well-known new uncertainties are introduced.

The model simulation was performed in a non-nested mode as in Hogrefe et al. (2001) with a horizontal grid-cell dimension of $3 \times 3 \mathrm{~km}$. The model covered a $60 \times 36 \mathrm{~km}$ area of the northeast of Spain in a domain extending from $2.1^{\circ} \mathrm{E}$ to $2.5^{\circ} \mathrm{E}$ and from $41.6^{\circ} \mathrm{N}$ to $42.1^{\circ} \mathrm{N}$ (Fig. 2). The vertical structure consisted of 8 vertical layers extending from the surface up to $3.5 \mathrm{~km}$.

The meteorological data was provided by the Penn State University/National Center of Atmospheric Research mesoscale Model (MM5), version 3.4 (Grell et al., 1993). Four domains two ways nested are defined using the following resolution: $27,9,3$ and $1 \mathrm{~km}$. To simulate the sea breeze, the dimensions of each domain are $31 \times 31$ grid points for the two outer domains, and $37 \times 43$ and $37 \times 61$ grid points for the two inner domains, respectively. The biggest domain is centred at $(41.70 \mathrm{~N}, 2.27 \mathrm{E})$ and the smallest domain covers an area from $41.6 \mathrm{~N}$ to $42.1 \mathrm{~N}$ (Fig. 2). The initial and boundary conditions are updated every six hours with information from the European Centre for Medium Range Weather Forecast (ECMWF) model with a $0.5^{\circ} \times 0.5^{\circ}$ resolution. For the two inner domains, we used a topography and land-use date base with 30 " resolution. For the two outer domains the horizon- tal resolution was 5'. High vertical resolution is prescribed in the atmospheric boundary layer with 14 levels. More details about the performance of the MM5 can be found in Soler et al. (2003). The meteorological outputs of the smallest domain are made compatible with the UAM-V grid configuration by performing interpolations along the horizontal and vertical levels.

\section{Emissions inventory}

The emissions were calculated over a domain of $50 \times 30$ horizontal cells of $3 \times 3 \mathrm{~km}^{2}$, covering an area of $150 \times 90 \mathrm{~km}^{2}$ (Fig. 1). Two types of emissions (anthropogenic and biogenic) were considered.

\subsection{Anthropogenic emission}

Anthropogenic emissions are basically produced by traffic and industrial activities. To calculate emissions for the traffic network, databases that make the distinction between motorways and roads were taken from the monthly traffic statistics (2000) provided by the Ministry of Public Works of the Spanish government and the Department of Territorial Policy and Public Works of the Catalan government. For motorways, the mean daily traffic intensity (MDI) is specified for heavy and light vehicles. For other roads, the database of the Statistical Institute of Catalonia (2000) provided the percentage of heavy and light vehicles, which are useful for calculating the MDI for heavy and light vehicles. We took the holiday periods into account by reducing the MDI by $30 \%$.

The emissions were therefore calculated from the following expression:

$E_{i}=\left(M H I_{h} * e_{i h}+M H I_{l} * e_{i l}\right) * L$

where:

- $E_{i}(\mathrm{~kg} / \mathrm{h})$ is the mass emission for a specific pollutant, time and section of the motorway.

- $M H I_{h}$ (number of vehicles per hour) is the mean hourly traffic intensity for heavy vehicles and $M H I_{l}$ (number of vehicles per hour) is the mean hourly traffic intensity for light vehicles. Both are directly calculated from MDI by assigning a percentage of the total traffic intensity to every hour (according to databases provided by the Spanish and the Catalan governments).

- $e_{i h}(\mathrm{~kg} / \mathrm{km})$ is the emission factor for heavy vehicles and $e_{i l}(\mathrm{~kg} / \mathrm{km})$ is the emission factor for light vehicles. According to the Emission Inventory Guidebook from EMEP/CORINAIR (1999), these factors depend on the vehicle's fuel consumption and the type of pollutant. Because hydrocarbon speciation is required, we used the emission factors from Sagebiel et al. (1996). 
- The fuel consumption depends on the type of fuel used by the vehicles. To determine the use of petrol or diesel by vehicles, we used information from the Directorate General for Traffic (2001).

- $L$ is the length of the stretch of motorway.

To take into account industrial emissions, we used information provided by the Catalan government about industrial activities. For every emitting source, the flow, emission level and industrial activity is specified. To calculate industrial emissions we used the following expression:

$E_{i}=f * n_{i}$

where $E_{i}(\mathrm{~kg} / \mathrm{h})$ is the hourly emission of a specific pollutant for a particular source, $f$ is the flow $\left(\mathrm{m}^{3} / \mathrm{s}\right)$ of the source and $n_{i}\left(\mathrm{ppm}\right.$ or $\left.\mu \mathrm{g} / \mathrm{m}^{3}\right)$ is the emission level for the pollutant.

\subsection{Biogenic emissions}

To estimate emissions from vegetation, we used the procedure described by Pierce et al., (1998). Only isoprene, the main biogenic VOC, and nitrogen oxide were considered.

To determine these emissions, we used the MM5 model to calculate the surface air and subsoil temperatures. We obtained the photosynthetically active radiation (PAR) from measured global radiation by assuming that $48 \%$ of global radiation is PAR (McCree, 1972). The same database as used for MM5 model provided land use classes (Dudhia et al., 2000).

\section{Applications of the models}

\subsection{Box model}

An initial pre-processed meteorological profile and hourly turbulent surface fluxes, calculated from the MASS model at 06:00 UTC (which corresponds to the grid point at which the photochemical model will be applied), are passed on to the transilient model, which supplies the time evolution of temperature, the wind speed, the turbulent heat flux profiles and the height of the mixing layer. Also, data transferred on line from the Doppler Sodar is used as a diagnosis tool for updating the wind forecast provided by the MASS model. At the same time, solar radiation and cloudiness fraction are very important in the formation of ozone, so RADAR and METEOSAT images are also used to improve ozone forecasting. Finally, all this information combined with emissions inventory is transferred to the photochemical model, which provides hourly ozone forecasts. During anticyclonic situations, when the main wind is the sea breeze, the polluted air mass transported from the industrial area south of La Plana is taken into account, and the box model is executed in Eulerian and Lagrangian forms. In this case, the trajectory followed by the column air mass starts in the south (M in Fig. 1) and ends in the Vic area (V in Fig. 1). We therefore applied the chemical Eulerian model in the Mollet area from 06:00 UTC to 10:00 UTC, at which point the sea breeze arrives and this idealized column moves with the wind (along the wind trajectory) and includes emissions as the column passes over various sources of emission. This column transports ozone and allows its advection along the way.

The box model was applied during the summer of 2001. We did not consider the summer of 2002 because some of the ground stations were out of order at that time. To evaluate the ozone forecast model in La Plana, we calculated statistics such as accuracy and bias. For daily peak ozone concentration, accuracy was $16 \mu \mathrm{g} / \mathrm{m}^{3}$ and bias was $3 \mu \mathrm{g} / \mathrm{m}^{3}$. When we evaluated the model forecast according to threshold or category, we found that accuracy was $90 \%$ and bias was 0.5 for $\left[\mathrm{O}_{3}\right]>180 \mu \mathrm{g} \mathrm{m}^{-3}$ and that accuracy was $86 \%$ and bias was 1.22 for $140<\left[\mathrm{O}_{3}\right] \leq 180 \mu \mathrm{g} \mathrm{m}^{-3}$. Bias lower than $1 \mathrm{in}-$ dicates that the model under-forecasts concentrations. Bias was greater than 1 for second threshold, in this case, the model overforecasts concentrations, i.e., ozone values really fall in a category lower than $140 \mu \mathrm{g} / \mathrm{m}^{3}$. The main causes of the discrepancies between measurements and simulations may be sources of errors such as indetermination in the emission model, uncertainties in the determination of the column depth or height of the mixing layer or cloudiness fraction

\subsection{Grid model}

We applied the modelling system MM5-UAMV for an ozone episode that occurred between 21 June and 23 June 2001. On these dates, the synoptic weather situation was characterized by high pressures. High pressures favour sunny days, which allow the total radiation to reach the surface, high temperatures, which accelerate reactions involving ozone and its precursors, and sea breeze development, which has a major role in the advection of pollutants from coastal industrialized areas. Although the models were applied in a single episode, we think that it corresponds to a typical and reiterative summer conditions, thus it is representative and relevant for the zone.

The simulation began at $0 \mathrm{~h}$ UTC on 21 June 2001 and ended at $23 \mathrm{~h}$ UTC on 23 June 2001. The model was run each day with different initial and boundary conditions, appropriately interpolated meteorological data provided by the MM5, and the same emissions inventory for the same grid by the method described in Sect. 4.

We used time-varying boundary conditions based on surface observations and typical range values in urban and rural areas (Finlayson-Pitts et al., 2000). We do not apply the model in a forecast mode, so it was an episode simulation. To use the model as a forecasting system the boundary conditions should be provide by other system.

The initial conditions were background concentrations based on information from the six monitoring stations inside the domain and typical values for the species without 

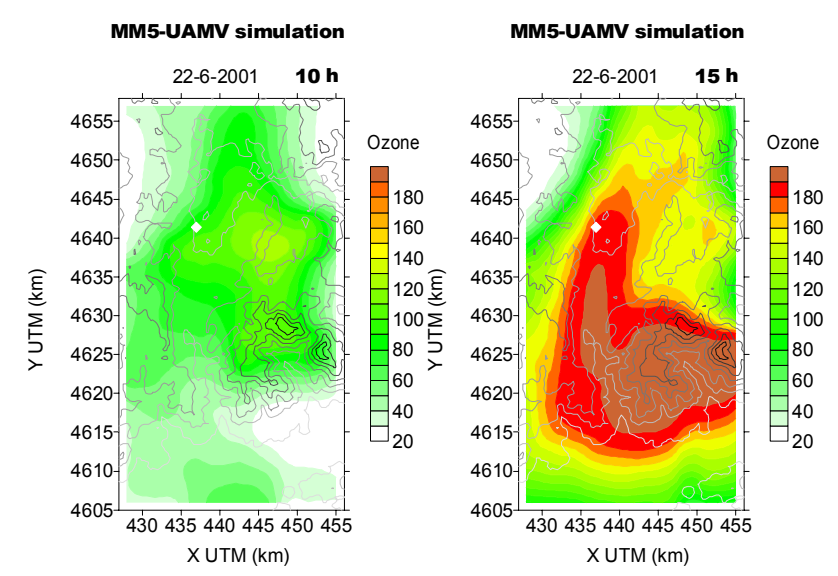

Fig. 3. Spatial distribution of ozone from UAMV simulation on 22 June, left panel at $10 \mathrm{~h} \mathrm{UTC}$ and right panel at $15 \mathrm{~h}$ UTC. The colour ozone scale is in $\mu \mathrm{g} \mathrm{m}^{-3}$ and the white rhombus show Vic location.

measurement. The second and third days began with the concentrations from the preceding day. In any case, the daily results for the model were not at all sensitive to the initial conditions.

The usages of the soil were identified with those used by MM5, a 25-category database of 30" resolution from the United States Geological Survey (USGS) i.e. each of the 25 types of MM5 was assigned to one of the 11 categories recognised by UAMV. This was done from the description of each category and from the roughness.

Figure 3 shows the model output for two different times. Figure 3 (left panel) represents the spatial distribution of ozone on the early morning of 22 June, when the sun radiation was weak and there was little formation of ozone. The predominant ozone concentrations were less than $80 \mu \mathrm{g} / \mathrm{m}^{3}$ and in some near contours areas they were less than $20 \mu \mathrm{g} / \mathrm{m}^{3}$. Those low levels of ozone are related to night destruction mainly due to titration effects and to low incoming radiation during morning hours. Figure 3 (right panel) represents the spatial distribution of ozone concentrations at 15 UTC. At this time the advection of air by the incoming sea breeze loaded with ozone precursors leads to high ozone concentrations. We can see the influence of the southern emissions in the central zone, which is rural and poorly inhabited. Note the major area of ozone concentration in dark red in the centre-left of the domain. This area has no measurement station, so we must be careful with this result. This area contains forested high mountain ranges, which emit large quantities of isoprens, and is strongly influenced by industrial emissions, so these high ozone concentrations are possible. To control and validate the results provided by the model in this area, an experimental campaign of measurements and some ground measurement stations should be required.

Figures 4, 5 and 6 compare the 3-day series of modelled ozone concentrations by UAMV with those observed at the
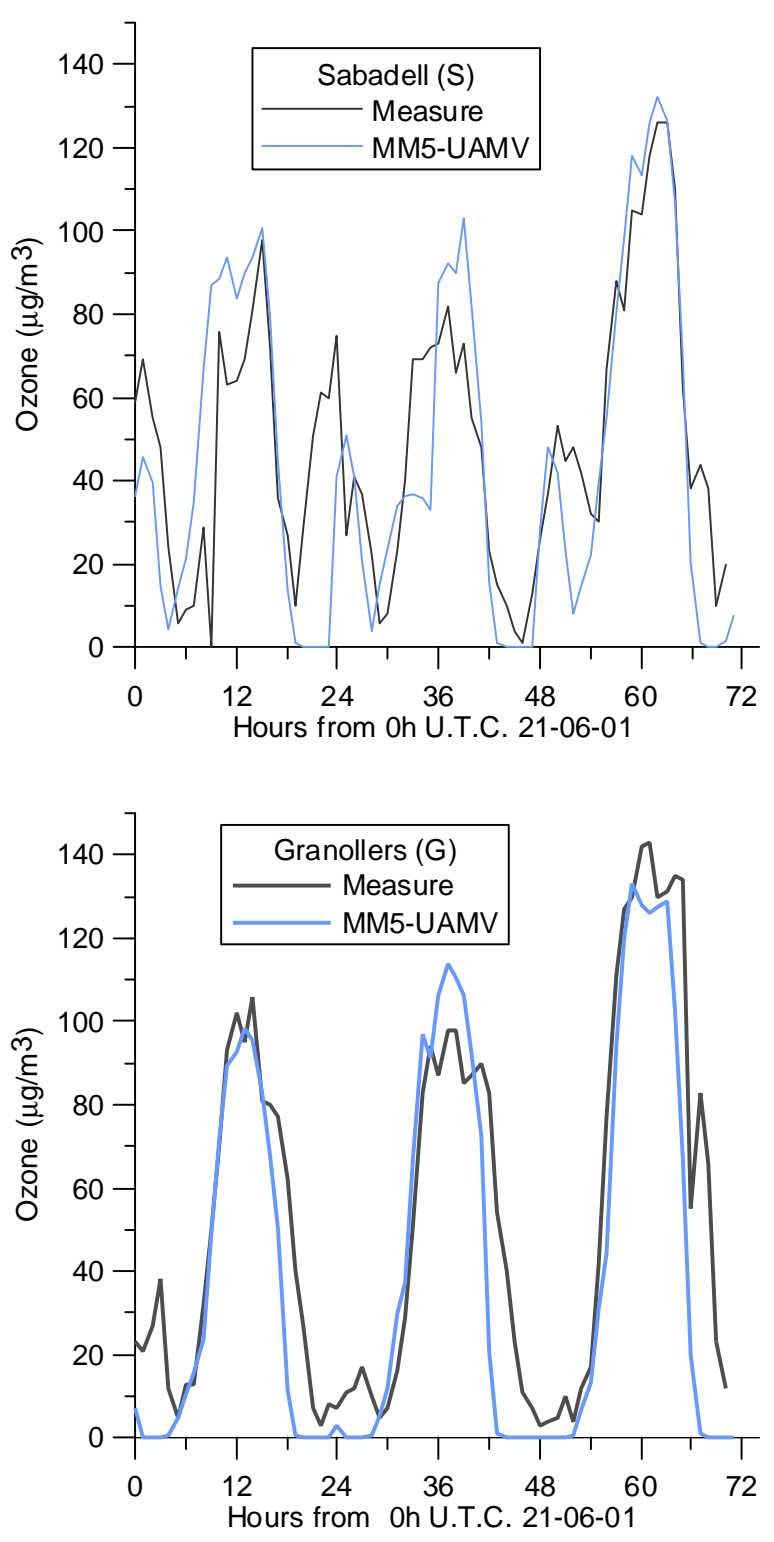

Fig. 4. Hourly ozone measurement (black) and UAMV prediction (blue) for days 21, 22 and 23 June 2001. The upper panel corresponds to Sabadell, and the lower to Granollers.

six monitoring stations inside the domain. Concentrations on the lowest level of the model, which is approximately $25 \mathrm{~m}$, are compared with the ambient data. Figures 4, 5 and 6 show the graphical validation of the MM5-UAMV performance for $72 \mathrm{~h}$, except for the Manlleu station (M), where, due to several problems, data were only available for the first $40 \mathrm{~h}$ (Fig. 6). Qualitatively, the model simulates the ozone patterns reasonably well, particularly at the Granollers $(\mathrm{G})$ station (Fig. 4). The low night values at the St. Celoni (C) (Fig. 5) and Granollers (G) stations were simulated well, as was the strong increment between the night time minimum and the day time peak. However, at Sta. M-a de Palautordera 

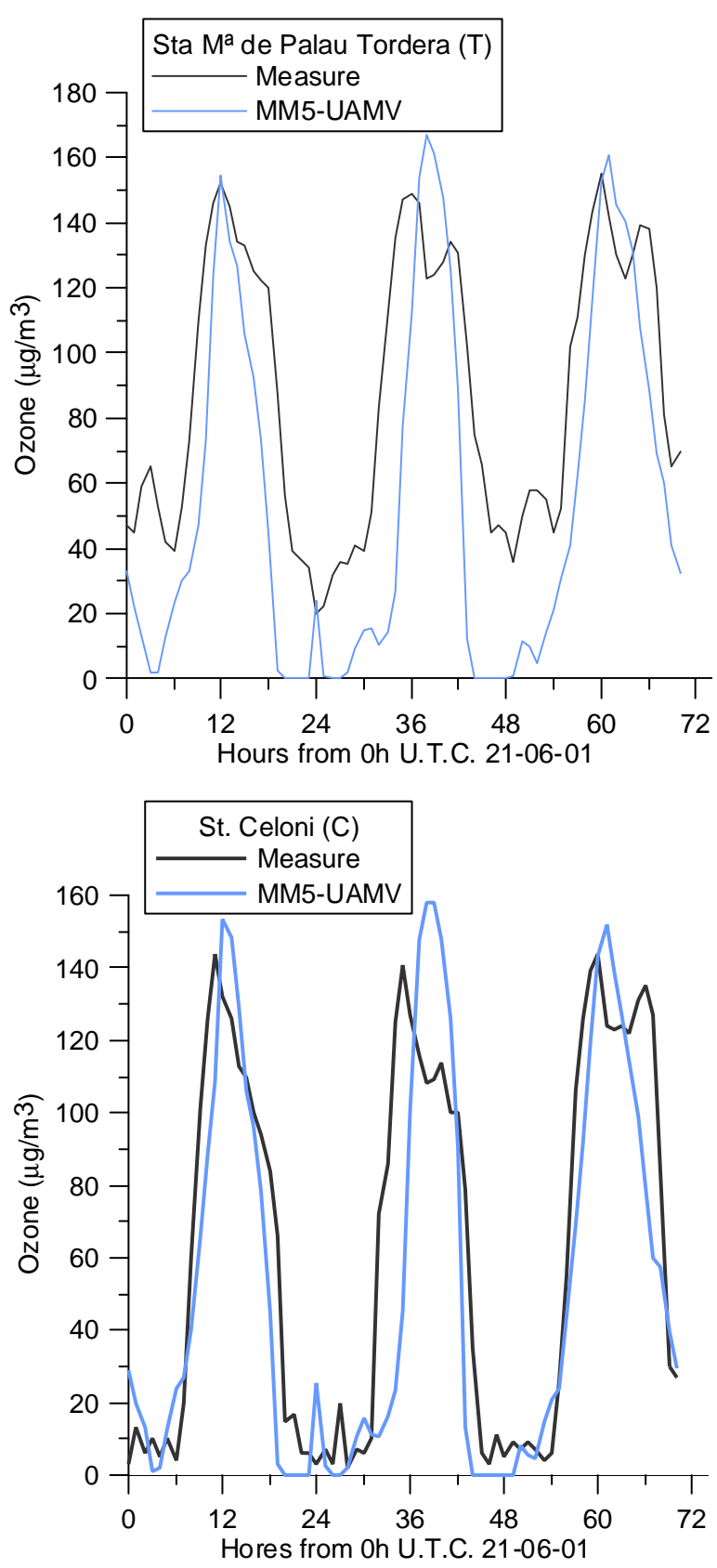

Fig. 5. Hourly ozone measurement (black) and UAMV prediction (blue) for days 21, 22 and 23 June 2001. The upper panel corresponds to Sta. Ma de Palau Tordera, and the lower to St. Celoni.

(T) (Fig. 5), the model overpredicted the night time minimum ozone concentration, perhaps because of the rural nature of the station and the lack of precursors at night time. In the day time, the model simulated the peak ozone concentrations quite accurately, especially in Vic (V) and Manlleu (M) (Fig. 6). As there are often high ozone values at these stations, this was one of the main goals of the simulation. Most of the stations in this study are closer to the boundary than
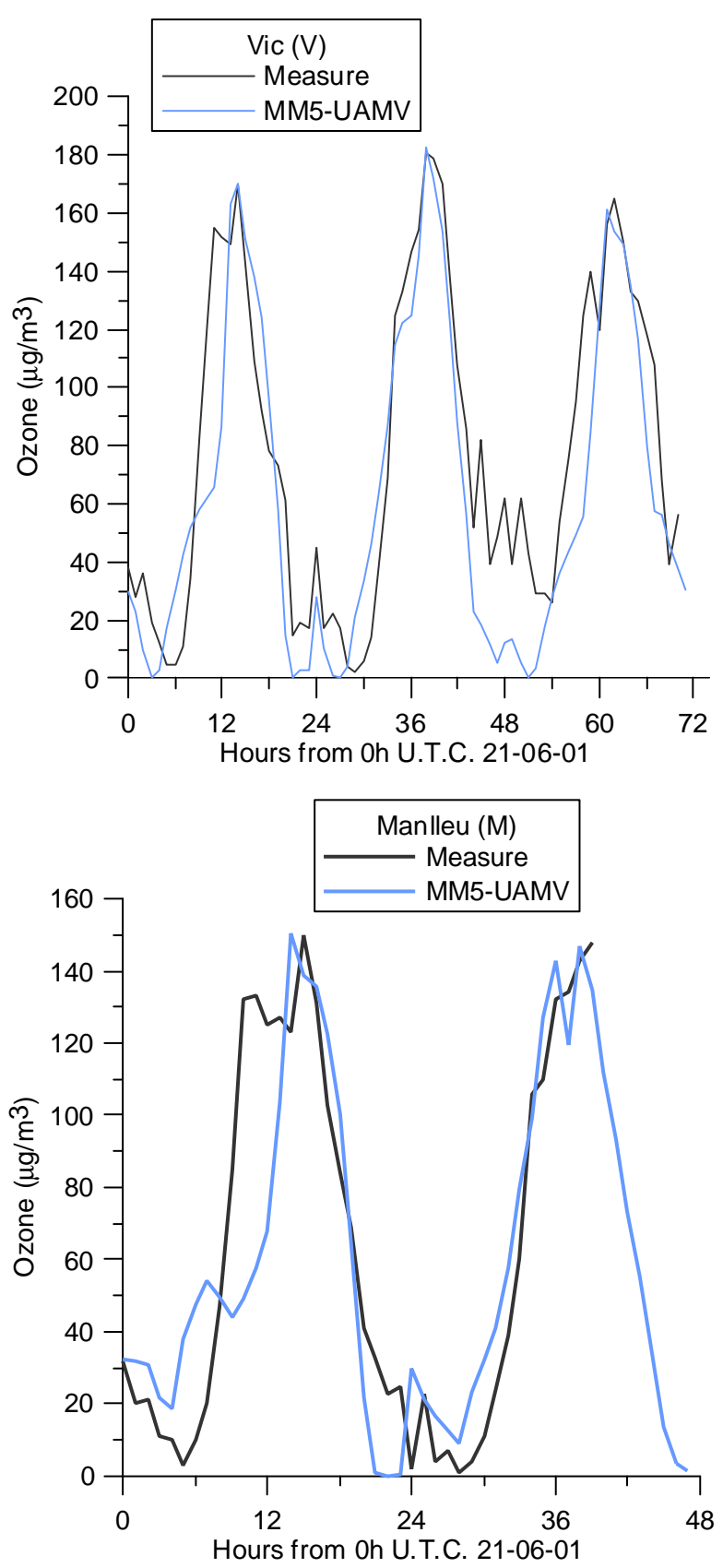

Fig. 6. Hourly ozone measurement (black) and UAMV prediction (blue). The upper panel corresponds to Vic, for days 21, 22 and 23 June 2001, and the lower to Manlleu, for days 21 and 22 June 2001.

those at Vic (V) and Manlleu (M) and, although the peak ozone concentrations were not simulated so accurately, we considered the slight mismatch in peak ozone concentrations to be quite normal in current models. A larger domain may reduce the influence of the contour on these cells.

As well as graphical methods, we used eight statistical criteria (Jiang et al., 1998) to evaluate the results showed in Table 1 . The negative values of mean bias and relative mean 
Table 1. Statistics results for MM5-UAMV performance.

\begin{tabular}{lr}
\hline & MM5-UAMV \\
\hline Mean Bias $\left(\mu \mathrm{g} / \mathrm{m}^{3}\right)$ & -13.2 \\
Relative Mean Bias $(\%)$ & -20.7 \\
Mean Gross Error $\left(\mu \mathrm{g} / \mathrm{m}^{3}\right)$ & 23.8 \\
Relative Mean Gross Error $(\%)$ & 36.6 \\
Bias for maximums $\left(\mu \mathrm{g} / \mathrm{m}^{3}\right)$ & 1.78 \\
Average Station Peak Normalized Bias $(\%)$ & 2.0 \\
Accuracy for maximum $\left(\mu \mathrm{g} / \mathrm{m}^{3}\right)$ & 7.23 \\
Average Station Peak Normalized Error $(\%)$ & 5.6 \\
\hline
\end{tabular}

bias indicate that the model tends to underestimate ozone concentration. This underestimation may be due to the low values estimated by the model at nightime, since the model estimates the peak ozone concentration well. We can see in Table 1 that the statistics related to the maximum concentration bias are small and positive. When the relative mean gross error was compared in other simulations e.g. in Jiang et al. (1998), a value of $34.8 \%$ was assigned to the CALGRID model and a value of $36.9 \%$ was assigned to the UAMV model in a four-day simulation. In our simulation, relative mean gross error was $36.6 \%$ for MM5-UAMV, which is the order of magnitude of the other two modelling systems. Our results were very good when we analysed the agreement of the peak ozone concentrations. An average station peak normalized error of $5.6 \%$ improved the results from these other simulations.

\section{Models comparison}

Because the box model predicted ozone only in La Plana, more specifically in the Vic area, we can compare the two models only in Vic (V). There are many differences between the models, but the greatest difference is the extension of the domains. While the box model was only used for forecasting in La Plana, the grid model was more widely used and shows the ozone in areas where there were no measurements. Also, the box model has been widely used as a forecasting tool. As it has been tested more often it has been improved by slight modifications and is now a model that represents real ozone concentrations. The grid model, on the other hand, is in its first stage of development and needs more work and more simulations to become an effective tool that provides accurate and reliable forecasts of ozone concentration. However, we have made a preliminary comparison. Figures 7, 8 and 9 show the daily ozone values predicted by both models and ozone measurements in Vic (V). Both models reproduced the ozone peak for the three days. However, the box model adjusted the measurements better during most of the daytime hours, while the grid model had a similar agreement

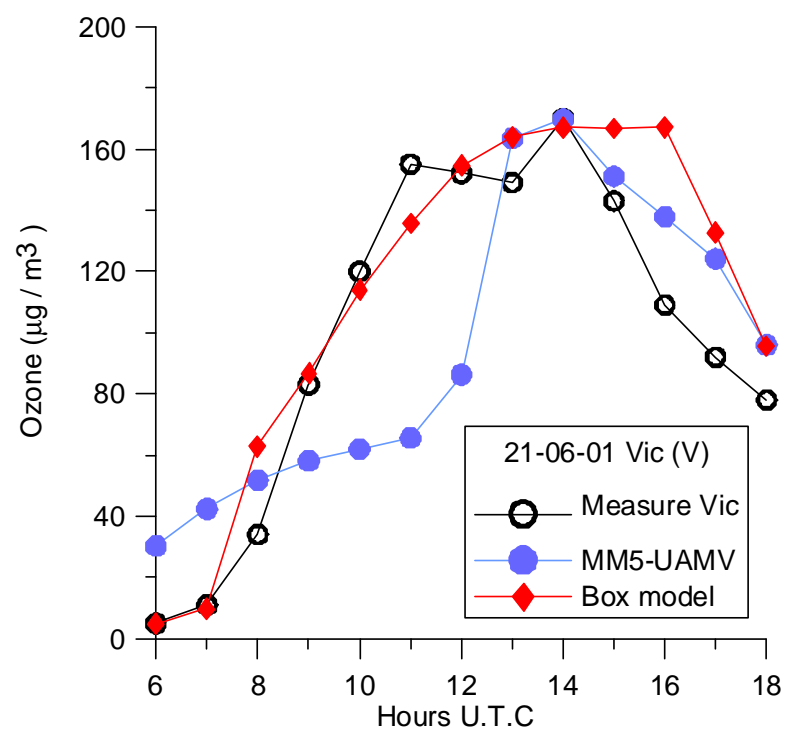

Fig. 7. Graphical comparison of ozone from measurement station (black), UAMV simulation (blue) and box model forecast (red), in Vic on 21 June 2001.

only for 22 June. These discrepancies may be due to the fact that the box model has been specifically adjusted for the Vic area, while the grid model represents the spatial distribution of ozone concentration in a larger domain, so it is more difficult to obtain an accurate diurnal concentration pattern. In addition to the graphical comparison, we have calculated some statistics for each model but, as the periods evaluated are different, the results may not be representative enough. In any case, we found that for the box model over the summer 2001 maximum concentration accuracy was $16 \mu \mathrm{g} / \mathrm{m}^{3}$ and bias was $3 \mu \mathrm{g} / \mathrm{m}^{3}$, and that for the grid model for the three days and the six stations considered in this study, maximum concentration accuracy was $7 \mu \mathrm{g} / \mathrm{m}^{3}$ and bias was $2 \mu \mathrm{g} / \mathrm{m}^{3}$.

\section{Conclusions}

The aim of this paper was to apply two models over an area characterized by a complex orography and affected by the presence of a nearby industrial area in which the sea breeze advects ozone and precursors to produce high ozone levels.

We analyzed the performances of a box model and a grid model in this area during different periods.

The box model was applied during the summer of 2001 in a nonoperative way but it was used in the summer of 2003 as a forecasting tool. This helped to adjust the model specifically for this area and the results over this longer period are quite satisfactory. Daily application of this model has shown that the main sources of error are indetermination in the emission model and in the height of the box model, but mainly in the cloudiness fraction, which is not accurately forecasted by the meteorological model. 


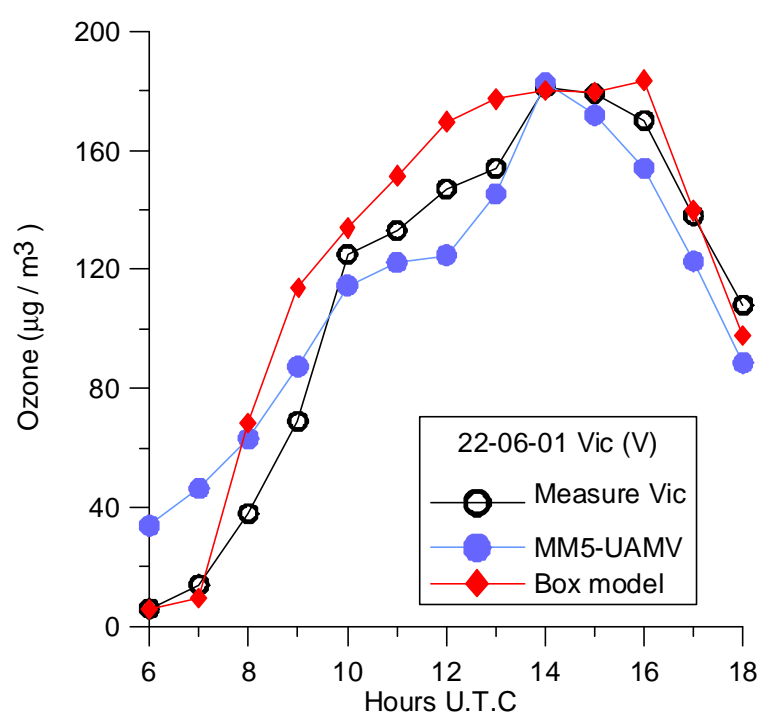

Fig. 8. Graphical comparison of ozone from measurement station (black), UAMV simulation (blue) and box model forecast (red), in Vic on 22 June 2001.

The grid model was used during an ozone episode on three days of the summer of 2001. Although this model is only in its first stage of development, our results demonstrate its capability as its performance was good over the area we studied. Grid models take into account a wider area and can therefore forecast ozone concentrations in several locations. This requires control and quantification in order to assess the scale of ozone impacts and develop control strategies. Although the performance of the model was tested for only a short period, we found that it was highly sensitive to boundary conditions and only slightly sensitive to initial conditions. We therefore made a great effort to adjust the model's boundary conditions, especially those regarding hydrocarbon speciation. We believe the performance of the model would improve if a larger domain were used. This would reduce the boundary effects because the La Plana area would not be so close. Another way to improve performance is to execute a nested simulation. This would require a great effort because a vast domain would have to be modelled. However, the model would be more operative because the boundary conditions for the inner domain (which would include La Plana) would come from this vast domain.

The comparison of the two models for the episode days showed good agreement between them and the measurement station. Although the box model reproduce the daily ozone behaviour better than the grid model, both maximum values are really close to the peak ozone measured.

To conclude, we should stress that we validated and compared the whole modelling systems, not just the photochemical models. The modelling system includes the meteorological model, the emission system and the photochemical model. In this way, we have demonstrated two systems with sufficient accuracy for predicting ozone concentrations.

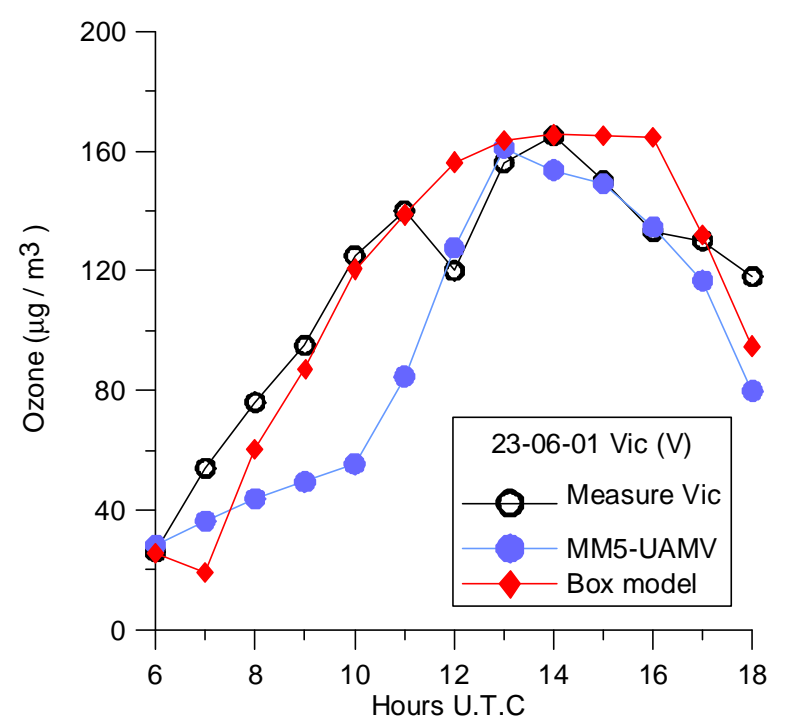

Fig. 9. Graphical comparison of ozone from measurement station (black), UAMV simulation (blue) and box model forecast (red), in Vic on 23 June 2001.

Acknowledgements. The forecasting project was supported by the "Departament de Medi Ambient" of the Catalan Government and by the Spanish Government through the project REN200303436/CLI. The authors are grateful to the very competent help of the "Medi Ambient" (Environment) Department technicians, especially C. Callés, S. Sánchez and J. Cot.

Edited by: J. Brandt

\section{References}

Alarcón, M., Alonso S., Cruzado A.: Atmospheric trajectory models for simulation of long-range transport and diffusion over the Western Mediterranean, Journal of Environmental Sciences and Health, A30, 9, 1973-1994, 1995.

Alarcón, M. and Alonso, S.: Computing 3-D atmospheric trajectories for complex orography: application to a case study of strong convection in the western Mediterranea, Computers \& Geosciences, 27, 583-596, 2001.

Blackadar, A. K.: Modelling the nocturnal boundary layer, Third Symposium on Atmospheric Turbulence, Diffusion and Air Quality, Raleigh, NC, Oct 19-22, American Meteorological Society, 46-49, 1976.

Blackadar, A. K.: Modelling pollutant transfer during daytime convection, Fourth Symposium on Atmospheric Turbulence, Diffusion and Air Quality, Reno, NV, Jan 15-18, American Meteorological Society, 443-447, 1979.

Berman, S., Ku, J. Y., Zhang, J., and Trivikrama, R.: Uncertainties in estimating the mixing depth - Comparing three mixing depth models with profiler measurements, Atmos. Envir., 31, 18, 30233039, 1997.

Biswas, J., Hogrefe, C., Rao, S. T., Hao, W., and Sistla, G.: Evaluating the performance of regional-scale photochemical modeling systems, Part III-Precursor predictions, Atmos. Envir., 35, 61296149, 2001. 
Biswas, J. and Rao, S. T.: Uncertainties in episodic ozone modelling stemming from uncertainties in the meteorological fields, J. Appl. Met., 40, 117-136, 2001.

EPA: Guideline for developing an ozone forecasting program, Office of Air Quality Planning and Standards, Research Triangle Park, N.C., EPA-254/R-99-009, July, 1999.

Chalita, S., Hauglustaine, D., LeTreut, H., and Muller, J.-F.: Radiative forcing due to increased tropospheric ozone concentrations, Atmos. Envir., 30, 1641-1646, 1996.

Codina, B., Aran, M., Young, S., and Redaño, A.: Prediction of a Mesoscale Convective System over Catalonia (Northeastern Spain) with a Nested Numerical Model, Meteor. Atm., 62, 9-22, 1997.

EMEP/CORINAIR Emission Inventory Guidebook: 3rd edition, 1999.

Department of Territorial Policy and Public Works of Spain: Monthly Traffic Statistics, (Estadística mensual de tràfic, 2000.), 2000.

Directorate General for Traffic, 2001: Anuario estadístico general, 2001.

Dudhia, J., Gill, D., Guo, Y. -R., Manning, K., Wang, W., and Chiszar, J.: PSU/NCAR Mesoscale Modeling System Tutorial Class Notes and User's Guide: MM5 Modeling System Version 3, National Center for Atmospheric Research, 2000, http://www.mmm.ucar.edu/mm5/documents/ MM5_tut_Web_notes/TutTOC.html, 138 pp, 2000.

Finlayson-Pitts, B. J. and Pitts., J. N.: Chemistry of the upper and lower atmosphere, Academic Press, 2000.

Gery, M., Whitten, G. Z., Killus, J. P., and Dodge, M. C.: A photochemical kinematics mechanism for urban and regional scale computer modeling, J. Geo. Res., 94, 12, 925-946, 1989.

Gery, M. W. and Crouse, R. R.: User's Guide for Executing OZIPR, US Environmental Protection Agency, Research Triangle Park, NC, EPA-9D2196NASA, 1990.

Grell, G. A.: Prognostic Evaluation of Assumptions used by Cumulus Parameterization, M Weath Rev, 121, 764-787, 1993.

Grossi, P., Thunis, P., Martilli, A., and Clappier, A.: Effect of sea breeze on air pollution in the greather Athens area: Part II: Analysis of different Emissions Scenarios, J. Appl. Met., 39, 4, 563$575,2000$.

Guderian, R., Tingey D. T., and Rabe R.: Effects of photochemical oxidants on plants in Air Pollution by Photochemical Oxidants, edited by Guderian, R., Springer, Berlin, 129-333, 1985.

Hewit, C., Lucas, P., Wellburn, A., and Fall, R.: Chemistry of ozone damage to plants, Chemistry and Industry, 15, 478-481, 1990.

Hogrefe, C., Rao, S. T., Kasibhatla, P., Kallos, G., Tremback, C. J., Hao, W., Olerud, D., Xiu, A., McHenry, J., and Alapaty, K.: Evaluating the performance of regional-scale photochemical modelling systems: Part I - metorological predictions, Atmos. Envir., 35, 4159-4174, 2001.

Jiang, W., Hedley, M., and Singleton, D. L.: comparison of the MC2/CALGRID and SAIMM/UAM-V photochemical modelling systems in the lower fraser valley, British Columbia, Atmos. Envir., 32, 17, 2969-2980, 1998.
Kaplan, M. L., Zack, J. W., Wong, V. C., and Tuccillo, J. J.: Initial results from a mesoscale atmospheric simulation system and comparisons with an AVE-SESAME I data set, M. Weath. Rev., 110, 1564-1590, 1982.

Ligocki, M. P. and Whitten, G. Z.: Modelling of Air Toxics with the Urban Airshed model, Air and Waste Management Association 85th Annual Meeting and Exhibition, Kansas City, Missouri, paper 92-84.12, 1992.

Ligocki, M. P., Schulhof, R. R., Jackson R. E., Jimenez, M. M., Whitten G. Z., Wilson, G. M., Myers T. C., and Fieber, J. L.: Modelling the Effects of Reformulated Gasoline on Ozone and Toxics Concentration in Baltimore and Houston Areas, (SYSAPP-92/127), 1992.

Lippmann, M.: Health effects of tropospheric ozone, Environ. Sci. Technol., 25, 12, 1954-1966, 1991.

McCree, K. J.: Test of current definitions of photosynthetically active radiation against leaf photosynthetically active radiation against lead photosynthesis data, Agr. For. Met., 10, 442-453, 1972.

Ministry of Public Works of the Spanish Government, 2000: Monthly traffic statistics, (Estadística mensual de tráfico, 2000.), 2000.

Pierce, T., Geron, C., Bender, L., Dennis, R., Tonnesen, G., and Guenter, A.: Influence of isoprene emissions on regional ozone modeling, J Geo Res, 103, D 19, 25 611-25 629, 1998.

Sagebiel, J. C., Zielinska, B., Pierson, W. R., and Gertler, A. W.: Real-world emissions and calculated reactivities of organic species from motor vehicles, Atmos. Envir., 30, 12, 2287-2296, 1996.

Silibello, C., Calori, G., Brusasca, G., Catenacci, G., and Finzi, G.: Application of a photochemical grid model to Milan metropolitana area, Atmos. Envir., 32, 11, 2025-2038, 1998.

Soler, M. R., Hinojosa, J., Bravo, M., Pino D., and Vilà Guerau de Arellano, J.: Analizing the basic features of different complex terrain flows by means a Doppler Sodar and a numerical model: Some implications to air pollution problems, Meteor. Atm., 85, 1-3, 141-154, 2003.

Statistical Institute of Catalonia: Anuari Estadístic, 2000.

Stockwell, R. W., Middleton, P., and Chang J. S.: The second generation Regional Acid deposition model, Chemical mechanism for regional air quality modeling, J Geo Res, 95, 16343-16367, 1990.

Stull, R. B.: Transilient Turbulence Theory, Part I: The Concept of Eddy Mixing Across Finite Distances, J. Atmos. Sci., 41, 33513367, 1984.

Stull, R. B. and Hasegawa, T.: Transilient Turbulence Theory, Part II: Turbulence Adjustment, J. Atmos. Sci., 41, 3368-3379, 1984.

Stull, R. B. and Driedonks, A. G. M.: Applications of the Transilient Turbulence Parameterization to Atmospheric Boundary Layer Simulations, Bound-Lay. M., 40, 209-239, 1987.

Zack, J. W. and Kaplan, M. L.: Numerical simulations of the subsynoptic features associated with the AVE-SESAME I Case, Part I: The preconvective environment, M. Weath. Rev., 115, 2367239, 1987. 